\title{
Relevância e aderência do mobile learning no Ensino Superior brasileiro: uma percepção estudantil em um curso de Design
}

\author{
Title: Relevance and adherence of mobile learning in the Brazilian Higher Education: a \\ student perception in a Design program
}

\author{
Maurício Elias Dick \\ Universidade do Estado de Santa Catarina (UDESC) \\ mauricioedick@gmail.com
}

\begin{abstract}
Resumo
Diversos aspectos da sociedade contemporânea estão mediados pelas tecnologias digitais. Computadores $e$ smartphones são utilizados diariamente para intermediar diferentes atividades, como a comunicação, o trabalho, a leitura e até mesmo os relacionamentos interpessoais. Por consequência, os dispositivos móveis se mostram cada vez mais presentes também nas salas de aula das universidades. Como resposta a esta realidade, verifica-se um movimento a nível mundial no sentido do uso de dispositivos móveis no ensino, o chamado mobile learning. De toda forma, é importante que a tecnologia seja incorporada de maneira crítica no processo de aprendizagem do estudante, pois é menos provável que os alunos adotem o mobile learning se para eles esse sistema tem pouco ou nenhum valor. Nessa perspectiva, esta pesquisa teve como objetivo inferir a percepção estudantil quanto à relevância e aderência do mobile learning no contexto do ensino superior brasileiro. Para tanto, realizou-se uma pesquisa experimental com 10 estudantes em uma disciplina teórica de um curso de graduação em Design em uma instituição de ensino superior pública brasileira. Como resultado, foi possível perceber que o mobile learning se mostrou aderente pelos referidos universitários, dado o amplo uso dos materiais disponibilizados. Além disso, a aprendizagem móvel foi considerada relevante e pertinente na percepção dos participantes, principalmente em razão das mobilidades física e temporal e da facilidade de acesso, mas também devido a economia financeira que ela permite.
\end{abstract}

Palavras-Chave: Ensino superior; Mobile learning; Percepção estudantil; Brasil.

\begin{abstract}
Several aspects of contemporary society are mediated by digital technologies. Computers and smartphones are used daily to mediate different activities such as communication, work, reading and even interpersonal relationships. As a result, mobile devices are increasingly present in the university classrooms as well. In response to this reality, there is a worldwide movement towards the use of mobile devices in education, called mobile learning. However, it is important that technology is incorporated in a critical way in the student's learning process, since students are less likely to adopt mobile learning if for them this system has little or no value. From this perspective, this research aimed to infer the student's perception of the relevance and adherence of mobile learning in the context of the Brazilian higher education. For that, an experimental research was carried out with 10 students in a theoretical course of an undergraduate Design program at a Brazilian higher education public institution. As result, it was possible to perceive that mobile learning was adherent to the referred university students, given the wide use of the materials available. In addition, mobile learning was considered relevant and pertinent according to the participants' perceptions, mainly due to physical and temporal mobility and ease of access, but also due to the financial savings it allows.
\end{abstract}

Keywords: Higher education; Mobile learning; Student perception; Brazil.

Cite as: Dick. M. L. (2019). Relevance and adherence of mobile learning in the Brazilian Higher Education: a student perception in a Design program (Relevância e aderência do mobile learning no Ensino Superior brasileiro: uma percepção estudantil em um curso de Design). Brazilian Journal of Computers in Education (Revista Brasileira de Informática na Educação - RBIE), 27(3), 191-211. DOI: 10.5753/RBIE.2019.27.03.191 


\section{Introdução}

Dado o desenvolvimento tecnológico atual, já é possível perceber que o cotidiano dos indivíduos é permeado pela presença de dispositivos computacionais, onde diversos aspectos da sociedade, como a cultura, a percepção e a experiência estão mediados pelas tecnologias digitais (Santaella, 2011). Computadores e smartphones são utilizados diariamente para mediar diferentes atividades, como a comunicação, o trabalho, a leitura e até mesmo os relacionamentos interpessoais. Nessa conjuntura, o digital se tornou o ambiente padrão para o indivíduo se comunicar, socializar-se e consumir conteúdos (Wischenbart, Carrenho, Celaya, Kong, \& Kovac, 2017).

No Brasil, um levantamento realizado pela empresa Delloite aponta que 92\% dos entrevistados possuem ou tiveram acesso recentemente a um smartphone (Delloite, 2018), enquanto no contexto internacional, um estudo indica que este número passa para $95 \%$ quando se consideram apenas os estudantes de graduação (Galanek, Gierdowski, \& Christopher Brooks, 2018). Por sua vez, pesquisas americanas mostram que quase dois terços dos estudantes do ensino superior utilizam seus smartphones para atividades de estudo (Mcgraw-Hill Education, 2016) e que a atividade mais comum inclui a leitura de materiais da disciplina (Magda \& Aslanian, 2018). Por consequência, os dispositivos móveis se mostram cada vez mais presentes também nas salas de aula das universidades.

Em resposta a esta realidade, verifica-se um movimento a nível mundial no sentido do uso de dispositivos móveis no ensino, o chamado mobile learning, como apontado pelo EDUCAUSE Horizon Report 2019 Higher Education Edition, relatório anual que traz tendências globais para a educação superior (Alexander et al., 2019). O mobile learning (ou m-learning) se apresenta como um sistema de aprendizagem que se apoia em dispositivos móveis (como smartphones e tablets) para instrumentalizar o ensino por meio de recursos tecnológicos digitais (Becker et al., 2017).

De toda forma, neste contexto, é importante ao professor universitário refletir a respeito da pertinência do uso de estratégias que envolvam o mobile learning no ensino superior. Afinal, como trazem Garcia, Rabelo, Silva, e Amaral (2011), a tecnologia deve ser incorporada de maneira crítica na educação, ou seja, o docente deve saber fazer escolhas conscientes das tecnologias no sentido de ponderar sua adoção no processo de aprendizagem do estudante. E, para isso, considerar a relevância de sua proposição para o aluno é fundamental, pois não basta ao professor disponibilizar os recursos tecnológicos, deve haver também aderência dos estudantes às suas estratégias. Nesse sentido, Crompton e Burke (2018) apontam que compreender a percepção dos alunos em relação ao uso da aprendizagem móvel é importante, pois é menos provável que os estudantes adotem o mobile learning se para eles esse sistema tem pouco ou nenhum valor.

Diversos estudos sobre a perspectiva dos estudantes em relação ao mobile learning já foram realizados. Ao se considerar as principais publicações relacionadas à aprendizagem móvel, a percepção estudantil é o segundo maior propósito das pesquisas e os estudantes de graduação são um grupo recorrente (Crompton \& Burke, 2018). No entanto, percebe-se que existe uma lacuna ao se considerar essa problemática a partir do contexto brasileiro. Nessa perspectiva surge o problema de pesquisa deste estudo: qual seria a percepção do aluno universitário brasileiro quanto à relevância e à aderência de estratégias de mobile learning na conjuntura de sala de aula?

De modo a responder a este questionamento, teve-se como objetivo geral inferir a percepção estudantil quanto à relevância e aderência do mobile learning no contexto do ensino superior brasileiro. Para tanto, realizou-se uma pesquisa experimental com 10 estudantes em 
uma disciplina teórica de um curso de graduação em Design em uma instituição de ensino superior pública brasileira.

\section{Trabalhos correlatos}

A perspectiva dos estudantes em relação à aprendizagem móvel é um propósito recorrente nos estudos ligados à temática "mobile learning”. Como afirmam Crompton e Burke (2018), ao se considerar os trabalhos publicados nos principais periódicos da área de educação tecnológica de 2010 a 2016, a segunda categoria mais proeminente de objetivos de pesquisa diz respeito à percepção estudantil. Entretanto, no estudo dos autores (Crompton \& Burke, 2018), não são citadas pesquisas brasileiras ou direcionadas ao contexto do país.

Diante desta observação inicial, buscou-se levantar pesquisas sobre o mobile learning no contexto do ensino superior brasileiro e, dentre estas, verificar se existiam resultados que tratassem da percepção dos estudantes quanto à relevância e aderência da aprendizagem móvel. Assim, realizou-se uma busca de forma sistematizada e abrangente na base de dados Scopus com a string "("mobile learning" OR "m-learning") AND ("higher education" OR "high education" OR "university" OR "college")" AND (Brazil OR Brazilian)", considerando-se a presença dos termos no título, resumo ou palavras-chave, sem limitação temporal. Nota-se que se optou pela referida base por se tratar do maior banco de documentos científicos do mundo (Elsevier, 2019). A busca retornou 10 resultados, dos quais se excluíram dois anais de eventos, resultando em 8 documentos.

Em razão do baixo número de textos, complementou-se a pesquisa nos anais do Simpósio Brasileiro de Informática na Educação (SBIE) de 2001 a 2018 e nas edições publicadas da Revista Brasileira de Informática na Educação (RBIE) de 1997 a 2019. Para ampliar o escopo, adicionaram-se sinônimos dos termos em português, resultando na string "("mobile learning" OR "m-learning" OR "aprendizagem móvel" OR "aprendizagem com mobilidade") AND ("ensino superior" OR "universidade" OR "faculdade" OR "higher education" OR "university" OR "college")". Nota-se que, como se tratavam de bases brasileiras, optou-se por retirar o limitador nacional da string aplicada no portal Scopus. Assim, o sistema do SBIE retornou 14 documentos e a base da RBIE trouxe 6 resultados. O Quadro 1 apresenta os estudos encontrados nas bases Scopus, SBIE e RBIE.

Quadro 1: Estudos encontrados considerando como temática o mobile learning no contexto do ensino superior brasileiro.

\begin{tabular}{|c|c|c|c|}
\hline Autores & Título & Ano & Fonte \\
\hline $\begin{array}{l}\text { Aarreniemi-Jokipelto, P., \& } \\
\text { Goulart, E. }\end{array}$ & $\begin{array}{l}\text { Localised Mobile Learning Solutions: Responding to the Needs of Global } \\
\text { Education }\end{array}$ & 2017 & SBIE \\
\hline $\begin{array}{l}\text { Alvarez, A.G., Dal Sasso, G.T.M., } \\
\text { Iyengar, M.S. }\end{array}$ & $\begin{array}{l}\text { Persuasive technology in teaching acute pain assessment in nursing: Results } \\
\text { in learning based on pre and post-testing }\end{array}$ & 2017 & Scopus \\
\hline $\begin{array}{l}\text { Arantes, F., Queiroz, D., da Silva, } \\
\text { A., \& Freire, F. }\end{array}$ & Usabilidade de Interfaces Responsivas para m-Learning & 2017 & SBIE \\
\hline Arantes, H., \& Seabra, R. & $\begin{array}{l}\text { TME: Aplicativo M-Learning para o Estudo de Conceitos Matemáticos } \\
\text { com Ênfase no ENEM }\end{array}$ & 2016 & SBIE \\
\hline $\begin{array}{l}\text { Barbosa, J., Hahn, R., Rabello, S., } \\
\text { Pinto, S. C. C., \& Barbosa, D. N. F. }\end{array}$ & Computação móvel e ubíqua no contexto de uma graduação de referência & 2007 & RBIE \\
\hline $\begin{array}{l}\text { Bartholo, V. F., Amaral, M. A., \& } \\
\text { Cagnin, M. I. }\end{array}$ & $\begin{array}{l}\text { Uma Contribuição para a Adaptabilidade de Ambientes Virtuais de } \\
\text { Aprendizagem para Dispositivos Móveis }\end{array}$ & 2009 & RBIE \\
\hline $\begin{array}{l}\text { Batista, S. C. F., Behar, P. A., \& } \\
\text { Passerino, L. M. }\end{array}$ & $\begin{array}{l}\text { M-learnMat: Modelo Pedagógico para Atividades de M-learning em } \\
\text { Matemática }\end{array}$ & 2012 & SBIE \\
\hline $\begin{array}{l}\text { Batista, S. C. F., Behar, P. A., \& } \\
\text { Passerino, L. M. }\end{array}$ & $\begin{array}{l}\text { M-learnMat: Aplicação de um Modelo Pedagógico para Atividades de M- } \\
\text { learning em Matemática }\end{array}$ & 2011 & SBIE \\
\hline
\end{tabular}

Continua 


\begin{tabular}{|c|c|c|c|}
\hline Autores & Título & Ano & Fonte \\
\hline $\begin{array}{l}\text { Junior, J. B., Coutinho, C., \& } \\
\text { Alexandre, D. }\end{array}$ & M-Learning e Webquests: as novas tecnologias como recurso pedagógico & 2006 & SBIE \\
\hline $\begin{array}{l}\text { Corrêa, A. G. D., de Oliveira, P. A., } \\
\text { Costa, L., Damon, D. L., \& de Deus } \\
\text { Lopes, R. }\end{array}$ & $\begin{array}{l}\text { Sistema de Avaliação Didática Acessível Portátil para Pessoas com } \\
\text { Deficiência Visual: estudo de caso com a plataforma Android }\end{array}$ & 2015 & SBIE \\
\hline Cruz, J., \& Rodrigues, W. & $\begin{array}{l}\text { Objetos de Aprendizagem Moveis Uma análise de requisitos funcionais } \\
\text { para auxiliar os desenvolvedores. }\end{array}$ & 2016 & SBIE \\
\hline $\begin{array}{l}\text { Da Silva, J.B., Rochadel, W., } \\
\text { Simão, J.P.S., Vaz Da Silva } \\
\text { Fidalgo, A. }\end{array}$ & $\begin{array}{l}\text { Adaptation model of mobile remote experimentation for elementary } \\
\text { schools }\end{array}$ & 2014 & Scopus \\
\hline $\begin{array}{l}\text { De Lima Ferreira, A.P., Diniz, } \\
\text { J.R.B., Franca, S.V.A. }\end{array}$ & M-learning supporting a culture of sustainable water consumption & 2016 & Scopus \\
\hline De Moura, V. A. B., \& Peres, L. M. & $\begin{array}{l}\text { Evaluation of the impact of retroaction in learning supported by an } \\
\text { educational tool }\end{array}$ & 2017 & RBIE \\
\hline $\begin{array}{l}\text { Gaspar, W., Oliveira, E., \& } \\
\text { Oliveira, K. }\end{array}$ & $\begin{array}{l}\text { Aprendizagem da Língua Portuguesa com Dispositivos Móveis: Um } \\
\text { Mapeamento Sistemático da Literatura }\end{array}$ & 2015 & SBIE \\
\hline Leite, B. S. & $\begin{array}{l}\text { M-Learning: the use of mobile devices as a didactic tool in the teaching of } \\
\text { chemistry }\end{array}$ & 2014 & RBIE \\
\hline $\begin{array}{l}\text { Machado, L.R., da Silva Mendes, } \\
\text { J.S., Sampaio, D.C.F., Grande, } \\
\text { T.P.F., Behar, P.A. }\end{array}$ & M-learning and the elderly: Construction of inclusive pedagogies & 2017 & Scopus \\
\hline $\begin{array}{l}\text { Marçal, E., de Lima, L., Júnior, M., } \\
\text { Viana, W., Andrade, R., \& Ribeiro, } \\
\text { J. W. }\end{array}$ & $\begin{array}{l}\text { A Utilização de Dispositivos Móveis com Ambientes Tridimensionais } \\
\text { como Ferramenta para Favorecer o Ensino de Hardware }\end{array}$ & 2009 & SBIE \\
\hline $\begin{array}{l}\text { Nicolete, P., Tarouco, L. M. R., \& } \\
\text { dos Santos, A. C. }\end{array}$ & $\begin{array}{l}\text { ossibilidades do App Inventor para a } \\
\text { el }\end{array}$ & 2018 & SBIE \\
\hline Oliveira, E., Diniz, J., Falcão, T. & $\begin{array}{l}\text { Teaching and learning through mobile devices in the field of law: A } \\
\text { systematic literature review | [Ensino e aprendizagem através de } \\
\text { dispositivos móveis no ramo do direito: Uma revisão sistemática da } \\
\text { literatura] }\end{array}$ & 2016 & Scopus \\
\hline Rachid, C. L., \& Ishitani, L. & m-tutorial: An Authoring Tool for m-learning Tutorial Development & 2012 & RBIE \\
\hline $\begin{array}{l}\text { Ribeiro, A. C. R., Sonego, A. H. S., } \\
\text { Machado, L. R., \& Behar, P. A. }\end{array}$ & $\begin{array}{l}\text { Pedagogical strategies for M-learning: A learning object aimed at teachers' } \\
\text { training | [Estratégias pedagógicas para A M-learning: Um objeto de } \\
\text { aprendizagem voltado para a formação de professores] }\end{array}$ & 2018 & Scopus \\
\hline $\begin{array}{l}\text { Ribeiro, P. D. S., Franciscato, F. T., } \\
\text { Mozzaquatro, P. M., \& Medina, R. } \\
\text { D. }\end{array}$ & Validação de um Ambiente de Aprendizagem Móvel em Curso a Distância & 2009 & SBIE \\
\hline $\begin{array}{l}\text { Scopel, M., Kratz, R., \& Pinto, S. } \\
\text { C. C. }\end{array}$ & $\begin{array}{l}\text { WSMEL: uma arquitetura para integração de serviços educacionais em } \\
\text { ambientes de M-Learning }\end{array}$ & 2006 & SBIE \\
\hline $\begin{array}{l}\text { Silva, F., da Silva, J. K. M., } \\
\text { Lucena, M., \& Gomes, A. }\end{array}$ & $\begin{array}{l}\text { Requisitos para Integração entre Ambientes de Aprendizado e m-Learning: } \\
\text { uma Revisão Sistemática da Literatura }\end{array}$ & 2015 & SBIE \\
\hline $\begin{array}{l}\text { Silva, L. C., Neto, F. M. M., \& } \\
\text { Júnior, L. J. }\end{array}$ & $\begin{array}{l}\text { MobiLE: A Mobile Learning Multi Agent Environment Based in Genetic } \\
\text { Algorithm to Support Ubiquitous Learning }\end{array}$ & 2013 & RBIE \\
\hline Vieira, D.V. & $\begin{array}{l}\text { Learning based on library automation in mobile Devices: The video } \\
\text { production by students of Universidade Federal do Cariri Library Science } \\
\text { Undergraduate Degree }\end{array}$ & 2017 & Scopus \\
\hline $\begin{array}{l}\text { Zanela Klein, A., Carlos Da Silva } \\
\text { Freitas, J., Luis Victoria Barbosa, J. }\end{array}$ & $\begin{array}{l}\text { M-learning in practice: Using SMS for teaching and learning in } \\
\text { undergraduate courses }\end{array}$ & 2015 & Scopus \\
\hline
\end{tabular}

Grande parte das pesquisas levantadas diz respeito (i) a revisões sistemáticas; (ii) a análises ou avaliações de aplicações, sistemas ou ambientes específicos; ou (iii) a propostas de sistemas, ferramentas, arquiteturas, requisitos funcionais, objetos de aprendizagem, modelos pedagógicos ou aplicações educacionais voltadas para dispositivos móveis. Cinco pesquisas, porém, tangenciam o foco deste estudo: a perspectiva dos estudantes quanto à aprendizagem móvel.

Leite (2014) apresenta uma percepção estudantil a respeito do mobile learning, mas a nível do ensino médio. Ribeiro, Sonego, Machado, e Behar (2018) trazem algumas possibilidades e contribuições do m-learning e do uso dos dispositivos móveis no ensino superior, apontadas pelos alunos participantes, sem abordar as percepções dos estudantes quanto à relevância da aprendizagem móvel. Aarreniemi-Jokipelto e Goulart (2017) apresentam um estudo piloto de avaliação de diferentes soluções de e-learning por alunos de variados níveis (ensino 
fundamental, técnico e superior) e apontam alguns benefícios do mobile learning a partir dos dados coletados, assim como Batista, Behar, e Passerino (2012, 2011) trazem vantagens do uso de celulares, observadas durante a avaliação de um modelo pedagógico com alunos de graduação. Todavia, ambos os estudos não tinham como principal propósito coletar tais percepções, portanto não as aprofundam.

Logo, não foram encontrados estudos que trouxessem como foco a percepção estudantil quanto à relevância e aderência do mobile learning e que, ao mesmo tempo, estivessem inseridos no contexto do ensino superior, apenas pesquisas tangentes ao propósito deste trabalho. Isto permitiu identificar tal oportunidade de investigação.

\section{Mobile learning: aprendendo em um contexto de mobilidade}

Aprender com mobilidade não é algo inovador por si só, pois esta característica sempre esteve presente nos livros, cadernos e outros instrumentos portáteis. Além disso, aproveitar diferentes contextos e momentos para aprendizagem também sempre foi uma prática comum aos indivíduos. De toda forma, com a evolução tecnológica, tornou-se possível a utilização de recursos computacionais em variados locais e momentos e, atualmente, é notável a presença generalizada de dispositivos móveis, como notebooks, smartphones, tablets, entre outros, e de redes sem fio de acesso à internet (Saccol, Schlemmer, \& Barbosa, 2011).

No contexto global, o brasileiro é aquele que mais tempo passa online em frente a um dispositivo móvel; em média, mais de 4h30 por dia (Armstrong, 2017), como mostra a Figura 1. Segundo Becker et al. (2017), toda essa penetração dos dispositivos móveis está alterando a maneira como as pessoas interagem com os conteúdos e com seus arredores.

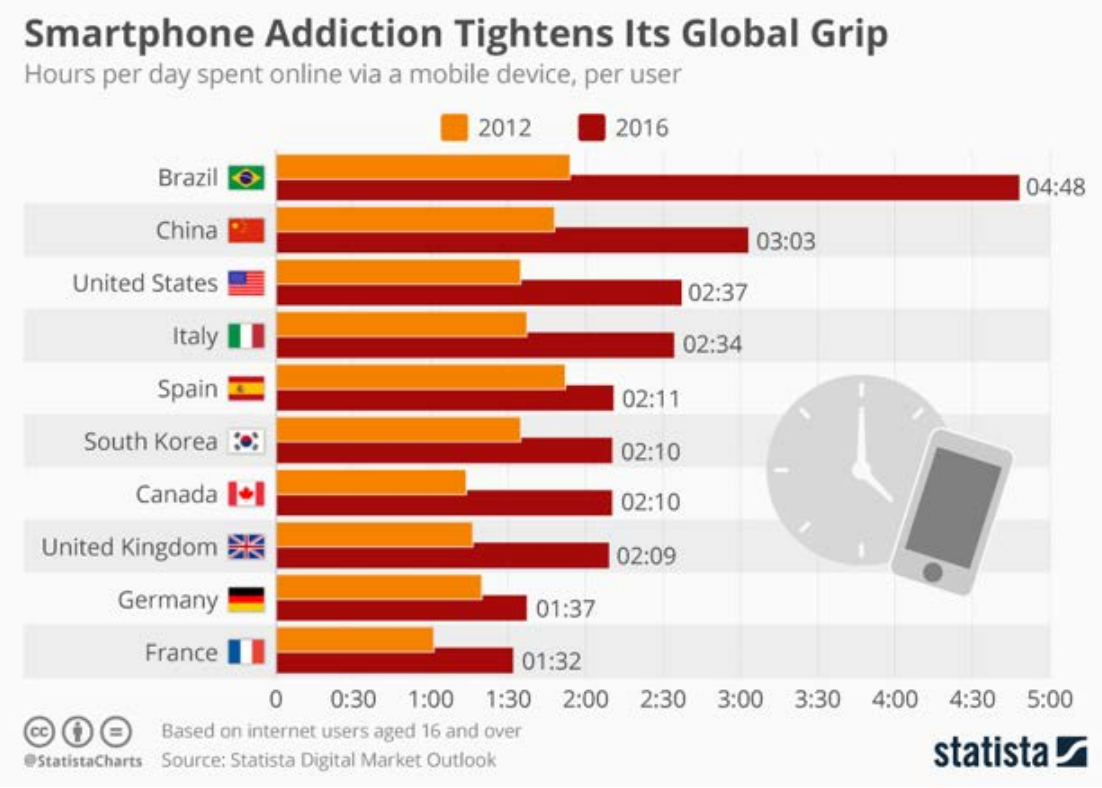

Figura 1: Horas online gastas por dia em diferentes países do mundo. Fonte: Armstrong (2017).

O atual desenvolvimento tecnológico também já permite acessar uma vasta gama de recursos multimídia e possibilidades de interação que oferecem um conjunto de possibilidades para a aprendizagem. Isto está alinhado com a mudança de perfil dos jovens aprendizes (Saccol et al., 2011), visto que é perceptível que as tecnologias digitais apresentam um caráter ubíquo na sociedade contemporânea (Costa, Duqueviz, \& Pedroza, 2015). Os chamados nativos digitais (Prensky, 2001) ou homo zappiens (Veen \& Vrakking, 2009) são os jovens que já nasceram 
rodeados pela maioria das tecnologias digitais hoje disponíveis, incluindo a internet, com as quais vivem conectados e que naturalmente fazem parte do seu dia-a-dia (Prensky, 2001). Para Veen e Vrakking (2009), essa geração cresceu utilizando múltiplos dispositivos tecnológicos, o que as permite ter controle sobre o fluxo de informações e se tornarem processadores ativos das mesmas.

Diante dessa realidade, Saccol et al. (2011) afirmam que é preciso repensar a educação, por meio de variadas mudanças, dentre estas, novas metodologias, práticas e processos de mediação pedagógica e avaliação. Nesse sentido, segundo os referidos autores, estudos têm mostrado que o uso de tecnologia móvel para aprendizagem produz efeitos positivos na motivação dos jovens estudantes. Crompton e Traxler (2018), por sua vez, são conclusivos: há na aprendizagem móvel um potencial revolucionário para a educação, especificadamente no contexto do ensino superior.

Assim, os processos de aprendizagem apoiados pelo uso de tecnologias da informação ou comunicação móveis e sem fio (notebooks, tablets, smartphones, etc.) são referidos como mobile learning, m-learning, aprendizagem móvel ou com mobilidade (Dias, 2014). Para Mülbert e Cybis (2011), mobile learning é "o uso educacional de dispositivos móveis e portáteis em atividades de ensino e aprendizagem” (p. 1). O que há de inovador, conforme KukulskaHulme (2005), são as possibilidades trazidas pelos dispositivos dentro de um contexto de portabilidade e mobilidade. Apesar disso, Mülbert e Cybis (2011) alertam que a caracterização de m-learning extrapola o contexto tecnológico.

Nessa direção, a característica fundamental do mobile learning é justamente a mobilidade, a qual permite aos estudantes não se limitar a um espaço de aprendizagem fixo ou formal, como explicam Saccol et al. (2011). Para os autores, porém, essa mobilidade não é apenas física, mas também temporal, dada a flexibilidade dos momentos de acesso; tecnológica, pela multiplicidade de dispositivos com os quais se pode acessar a informação; conceitual, em razão da variedade de conceitos e conteúdos que se pode acessar ao mesmo tempo; e sociointeracional, dada a interação simultânea com diferentes grupos sociais que a tecnologia móvel permite.

Além disso, o mobile learning se caracteriza por prover maior controle e autonomia ao sujeito, permitir uma aprendizagem em contexto - nas condições mais adequadas ao aprendiz -, admitir continuidade e conectividade entre estes diferentes contextos, bem como possibilitar uma aprendizagem mais espontânea, de acordo com interesses e necessidades do estudante (Saccol et al., 2011). Similarmente, para Kukulska-Hulme (2005), a aprendizagem móvel pode ser espontânea, pessoal, informal, contextual, portátil, ubíqua e integrada.

Essa conjuntura pode potencializar ainda mais o aprender, "justamente em função da maleabilidade do tempo e do espaço, da facilidade do acesso, da produção e troca de informações, do compartilhamento de experiências, ideias e da socialização de conhecimentos, entre outros" (Saccol et al., 2011, p. 8). No contexto universitário, a utilização de dispositivos móveis facilita a comunicação entre docentes e estudantes, o que acaba cativando-os e motivando-os para o processo de ensino e aprendizagem (Sousa, 2014).

Por outro lado, Saccol et al. (2011) alertam que o uso de uma nova tecnologia no contexto pedagógico não garante, por si só, inovação educacional. É necessário que se mantenha uma visão crítica à compreensão dos significados e usos que estas tecnologias representam para a educação, tanto no que tange às suas possibilidades quanto limitações. Afinal, a revolução no educacional não ocorre pela simples inserção de aparatos tecnológicos no contexto educativo, mas sim por meio do seu uso crítico e consciente. Isto posto, é fundamental superar a concepção instrumental de que a tecnologia é um simples suporte para disponibilizar informações e conteúdos (Garcia et al. 2011). 
Por isso, é importante verificar em que momentos e contextos estratégias que envolvam determinada tecnologia são relevantes para apresentar resultados superiores se comparadas a outros meios tecnológicos ou não. Além disso, é preciso estar atento à distração por parte dos estudantes, provocada pelo uso de tecnologias móveis, sendo um risco que deve ser gerenciado na adoção do mobile learning, por exemplo (Saccol et al., 2011). Como outras práticas didáticas, escolhas tecnológicas como o uso do mobile learning nos processos de ensino e aprendizagem devem estar de acordo com as concepções epistemológicas do conjunto docente-instituição, estando ligadas a questões como metodologias, práticas e processos de mediação. De acordo com a tecnologia utilizada, portanto, estarão disponíveis recursos e potencialidades que poderão privilegiar dadas práticas em prejuízo de outras (Saccol et al., 2011).

Em suma, a tecnologia móvel faz parte do panorama global na sociedade contemporânea e a educação deve refletir este contexto. Logo, os processos de ensino e aprendizagem necessitam responder a esta mudança frente a um mundo de mobilidade e conexão (Traxler, 2013) de modo a adequar-se ao novo perfil do jovem aprendiz.

\section{Procedimentos metodológicos}

Com o objetivo de inferir a percepção estudantil quanto à relevância e aderência do mobile learning no contexto do ensino superior brasileiro, esta pesquisa tem caráter experimental, se classifica como aplicada e é de abordagem qualitativa (Freire, 2013; Gil, 2008), pois possui interpretação indutiva de dados. Em relação aos procedimentos metodológicos, adotou-se inicialmente o método de revisão bibliográfica. Numa segunda fase, realizou-se uma pesquisa de campo com estudantes universitários, onde foram disponibilizados objetos de aprendizagem otimizados para dispositivos móveis, com o objetivo de obter dados quanto à relevância e a aderência destes materiais. Assim, foram adotadas as seguintes etapas metodológicas.

- Formulação dos instrumentos de pesquisa (objetos de aprendizagem e questionário);

- Aplicação do teste piloto para verificar a clareza do questionário;

- Disponibilização dos objetos de aprendizagem;

- Aplicação dos questionários;

- Compilação e análise dos resultados.

A pesquisa foi realizada com a participação voluntária de 10 estudantes universitários regularmente matriculados em uma disciplina teórica de um curso de graduação em Design, modalidade presencial, turno vespertino, pertencente a uma instituição de ensino superior pública brasileira. Nota-se que a turma era composta por um total de 11 alunos, portanto, um estudante optou por não participar do estudo. A escolha se deu por conveniência de acesso dos pesquisadores, tendo o experimento e a coleta de dados ocorridos durante um mês e dez dias.

\subsection{Instrumentos de pesquisa}

Para a realização do experimento, inicialmente formularam-se três objetos de aprendizagem ${ }^{1}$ diferentes, a serem disponibilizados aos estudantes em momentos distintos ao longo da disciplina: o primeiro para discussão em sala de aula, o segundo para a realização de uma

\footnotetext{
${ }^{1}$ Como o objetivo do experimento não fora avaliar os objetos, nem o processo de aprendizagem ou o aprendizado em si, o desenvolvimento dos objetos não foi pautado em recomendações ou parâmetros existentes na literatura.
} 
resenha-resumo e o terceiro para estudo de parte do conteúdo exigido em uma prova escrita individual. Optou-se por estes três diferentes contextos de uso para que fosse possível verificar se haveria diferença de aderência de acordo com a atividade solicitada.

Em razão da limitação temporal desta pesquisa, os objetos desenvolvidos consistiram em versões otimizadas para dispositivos móveis de textos necessários para a realização das atividades didáticas propostas. Com isso, possibilitar-se-ia o mobile learning, ainda que de baixa complexidade.

Os três textos foram então selecionados e desenvolvidos em versões para impressão e para leitura em dispositivos móveis. Especificamente, os textos foram ofertados da seguinte forma:

- Texto 01 (para discussão): uma versão para impressão e uma versão para leitura em smartphones;

- Texto 02 (para resenha-resumo): uma versão para impressão, uma versão para leitura em tablets, uma versão para leitura em smartphones e uma versão adaptável para qualquer dispositivo portátil (notebook, tablet, smartphone ou e-reader);

- Texto 03 (para prova): uma versão para impressão, uma versão para leitura em smartphones e uma versão adaptável para qualquer dispositivo portátil (notebook, tablet, smartphone ou e-reader).

Nota-se que nas versões para dispositivos específicos e para impressão, utilizou-se o formato PDF. Já nas versões adaptáveis, utilizou-se o formato EPUB ${ }^{2}$. Além disso, os objetos eram compostos majoritariamente por conteúdo textual, como descrito anteriormente.

Finalizados os objetos de aprendizagem para dispositivos móveis, foi formulado o questionário para coleta de dados a ser aplicado após o experimento com os estudantes. Composto por 17 perguntas fechadas de múltipla escolha (com possibilidade de adição de resposta) e uma pergunta aberta, o instrumento buscou levantar o perfil dos participantes, compreender o uso do smartphone na universidade e entender a aderência e a percepção estudantil quanto ao mobile learning no contexto do experimento.

O questionário foi dividido em três partes, onde a primeira buscou inferir o perfil do participante e sua relação com a tecnologia. Assim, além de idade e gênero, elaboraram-se perguntas que trouxessem dados em relação aos dispositivos móveis que o participante possuía, sua frequência de uso $^{3}$, se ele utilizava o smartphone para leitura (tanto de textos curtos notícias, mensagens, etc. - quanto longos - livros, artigos, etc.) e se o levava à universidade.

Se o participante respondesse que não levava o smartphone à universidade, ele seria encaminhado à terceira parte do questionário. Caso contrário, continuaria para a parte seguinte. Nela, o questionário procurou compreender o uso que o estudante fazia do seu smartphone na universidade. Assim, o instrumento trazia perguntas relacionadas ao uso do smartphone dentro

\footnotetext{
${ }^{2}$ EPUB é um formato de arquivo digital específico para e-books criado pelo IDPF (International Digital Publishing Forum). Em sua versão mais recente, o formato suporta imagens, áudios e vídeos, além de outros recursos de navegação e interação, sendo compatível com múltiplos dispositivos e plataformas de leitura (International Digital Publishing Forum [IDPF], 2017).

${ }^{3}$ Nesta pergunta, o participante deveria ordenar seus dispositivos de acordo com a frequência de uso, podendo apontar aqueles que não possuísse ou não tivesse acesso.
} 
da instituição e da sala de aula, bem como as atividades realizadas com o dispositivo em ambos os contextos. A Figura 2 apresenta as duas primeiras partes do questionário.

\section{M-learning no contexto universitário}

\section{Perfil do participante}

1. Gênero *

Marcar apenas uma oval.

$\bigcirc$ Feminino

Masculino

$\bigcirc$ Outro

Prefiro não responder.

2. Qual é a sua idade?* Marcar apenas uma oval.

17 anos ou menos.
18 anos
19 anos
20 anos
21 anos
22 anos
23 anos
24 anos
25 anos ou mais.
Quais destes dispositivos você possui?
Marque todos os que você possui ou tem
acesso para utilizar no seu dia-a-dia.
Marque todas que se aplicam.
$\square$ Smartphone
$\square$ E-reader (Kindle, Kobo, Lev, etc.)
$\square$ Tablet
$\square$ Computador portátil (notebook/laptop,
netbook, ultrabook)
$\square$ Computador de mesa (desktop)
$\square$ Não possuo nem tenho acesso para
utilizar nenhum dos dispositivos listados.

4. Conforme o uso, ordene os dispositivos que você utiliza com mais frequência. * Considere "1" o dispositivo que você mais utiliza. Marque apenas um dispositivo mais cada número.

Marcar apenas uma oval por linha.

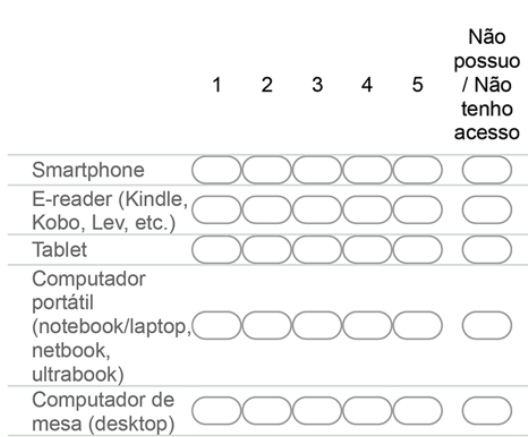

5. Você leva seu smartphone à

universidade?*

Marcar apenas uma oval.

$\bigcirc$ Sim, eu levo. Após a última pergunta desta seção, ir para a pergunta 7.

Não levo. Após a última pergunta desta seção, ir para a pergunta 10.

Não possuo um smartphone.

Após a última pergunta desta seção, ir para a pergunta 10.

6. Você utiliza o seu smartphone para leitura? *

Considere noticias, mensagens, etc. como "textos curtos" e livros, artigos, etc. como "textos longos".

Marcar apenas uma oval.

Sim, de maneira geral para textos curtos.

Sim, tanto para textos curtos quanto para textos longos.

$\bigcirc$ Não.

\section{Uso de smartphone na} universidade

7. Para quais destas atividades você utiliza seu smartphone enquanto está na universidade (fora da sala de aula)?

Marque todas as respostas que se aplicam. Marque todas que se aplicam.

$\square$ Me comunicar com familiares, colegas, amigos e outras pessoas.

$\square$ Jogar jogos

$\square$ Tirar fotografias.

$\square$ Navegar na internet e nas redes sociais.

$\square$ Realizar pesquisas na internet

Ler textos solicitados pelo professor.

$\square$ Fazer trabalhos/exercícios das disciplinas.

Outro:

8. Você utiliza o seu smartphone durante as aulas?

Marcar apenas uma oval.

Sim.

Não

9. Durante as aulas, que atividades você realiza no seu smartphone? *

Marque todas as respostas que se aplicam. Se você NÃO utiliza, marque apenas "Não utilizo o smartphone em sala de aula". Marque todas que se aplicam.

$\square$ Não utilizo o smartphone em sala de aula.

$\square$ Me comunicar com familiares colegas, amigos e outras pessoas.

$\square$ Tirar fotografias.

Jogar jogos.

$\square$ Navegar na internet e nas redes sociais.

Realizar pesquisas na internet.

Ler textos solicitados pelo professor.

Fazer trabalhos/exercícios da aula.

Outro:

Figura 2: Primeira e segunda parte do questionário. Fonte: autor com base na pesquisa realizada.

Já a terceira e última parte do instrumento de coleta de dados dizia respeito ao experimento de m-learning a partir dos textos disponibilizados pelo professor para a realização das atividades propostas. Dessa forma, conceberam-se questões que mostrassem se os alunos fizeram uso dos objetos de aprendizagem para dispositivos móveis e se acharam a sua disponibilização otimizada pertinente/relevante. Junto a isso, procurou-se também obter os motivos/razões para suas respostas, tanto do uso ou não-uso quanto da relevância/pertinência ou falta desta. Ao final, fora disponibilizado um campo de resposta aberta para comentários que os participantes julgassem pertinentes (Figura 3). 


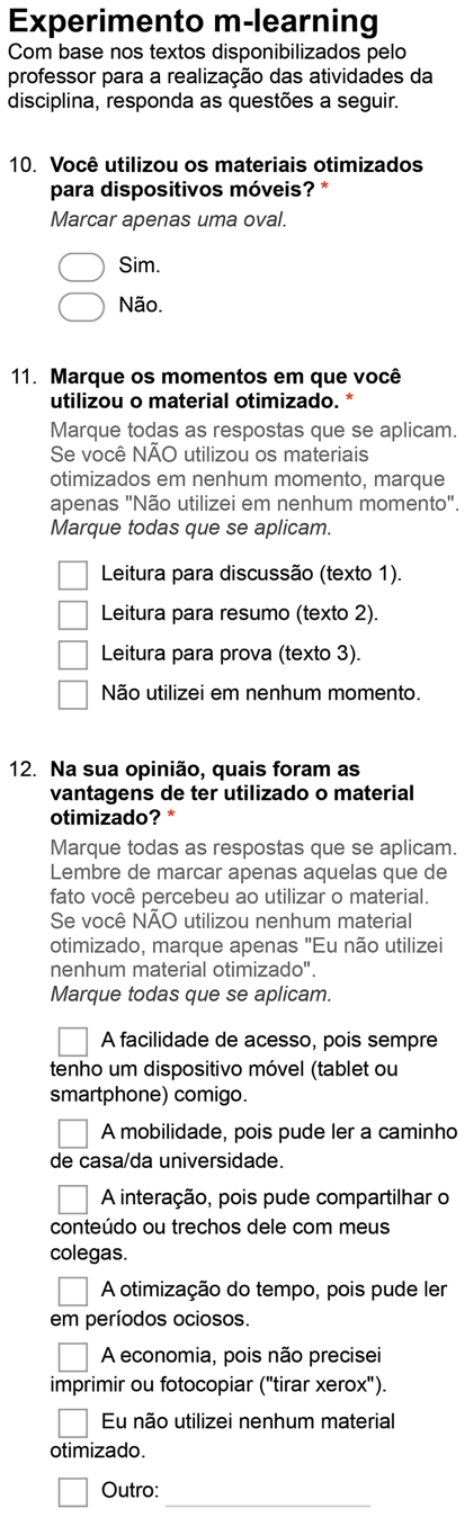

13. Se NÃO utilizou, por quê? *

Marque todas as respostas que se aplicam. Se você utilizou todos os materiais otimizados, marque apenas "Eu utilizei todos os materiais otimizados". Marque todas que se aplicam.

$\square$ Para a atividade pedida, a leitura no smartphone ou tablet não era adequada.

$\square$ Não gosto de ler no smartphone ou tablet, pois é desconfortável.

$\square$ Não percebi ou não lembrei que havia o material otimizado.

O material era muito extenso para ler no smartphone ou tablet.

$\square$ Não quis utilizar meu plano de dados (3G, 4G).

$\mathrm{O}$ WiFi não funcionou

Não consegui abrir o arquivo, meu smartphone ou tablet não era compativel.

$\square$ Eu utilizei todos os materiais otimizados.

$\square$ Outro:

14. Você achou relevante/pertinente a disponibilização do material otimizado?

Marcar apenas uma oval.

Sim, pois utilizei o material otimizado.

Sim, ainda que eu NÃO tenha utilizado o material otimizado.

$\bigcirc$ Não, pois NÃO utilizei o material otimizado.

Não, mesmo que eu tenha utilizado o material otimizado.

15. Por que você acha relevante/pertinente? Marque todas as respostas que se aplicam. Se você NÃO acha relevante/pertinente, marque apenas "Não acho

relevante/pertinente

Marque todas que se aplicam

Pela facilidade de acesso, pois sempre tenho um dispositivo móve (smartphone ou tablet) comigo.

Pela mobilidade, pois posso ler/estudar a caminho de casa/da universidade

Pela interação, pois posso facilmente compartilhar o conteúdo ou trechos dele com meus colegas.

$\square$ Pela otimização do tempo, pois posso ler/estudar em periodos ociosos.

Pela economia, não preciso gastar com impressão ou fotocópia ("xerox").

Não acho relevante/pertinente.

Outro:
16. Por que você NÃO acha relevante/pertinente?

Marque todas as respostas que se aplicam. Se você acha relevante/pertinente, marque apenas "Acho relevante/pertinente".

Marque todas que se aplicam.

Smartphones e tablets não são adequados para serem utilizados em sala de aula.

$\square$ Smartphones ou tablets não propiciam um estudo adequado.

$\square$ A leitura em smartphones ou tablets é ruim

$\square$ Smartphones e tablets dispersam a atenção.

Acho relevante/pertinente

Outro:

17. Para quais atividades você acha adequado o uso de smartphones ou tablets em sala de aula ou no contexto universitário?

Marque todas as respostas que se aplicam. Se você não acha adequado, marque apenas "Não acho adequado nestes contextos".

Marque todas que se aplicam

$\square$ Para a leitura de textos

Para a realização de exercícios.

$\square$ Para pesquisa.

Para estudo.

Não acho adequado nestes contextos.

Outro:

18. Comentários adicionais

Utilize este espaço para adicionar

quaisquer comentários adicionais

relacionados ao experimento realizado

durante a disciplina.

Figura 3: Terceira parte do questionário. Fonte: autor com base na pesquisa realizada.

\subsection{Aplicação do teste piloto e disponibilização dos objetos de aprendizagem}

Após sua elaboração inicial, o questionário foi submetido a um teste piloto para verificar a clareza de suas perguntas. O teste foi realizado com um estudante voluntário, não integrante do grupo pesquisado, e não resultou em alterações na forma e no conteúdo do questionário, o qual permaneceu em seu teor original.

Iniciado o experimento, os textos foram disponibilizados aos estudantes antes da realização ou entrega das respectivas atividades, podendo ser acessados e utilizados onde e 
quando lhes fosse mais conveniente. Assim, o texto 01 foi ofertado com dois dias de antecedência para discussão em sala de aula. Posteriormente, o texto 02 foi disponibilizado 14 dias antes da entrega da respectiva resenha-resumo. Na sequência, o texto 03 foi liberado seis dias antes da realização de prova. Nota-se que no dia desta atividade também foi permitido aos estudantes o acesso ao texto 03, tanto em sua versão impressa quanto digital.

Todos os alunos tiveram acesso aos materiais em uma pasta online disponível durante todo o período da disciplina. Destaca-se que, como os textos foram ofertados tanto em versão para impressão quanto para leitura em dispositivos móveis, os alunos possuíam diferentes formas de acessar o mesmo conteúdo. Optou-se por tal estratégia de modo a investigar se os aprendizes optariam pela versão otimizada ou não e por quê, além de buscar compreender se eles achariam relevante essa disponibilização ou não.

\subsection{Aplicação do questionário}

Encerrado o período de realização das atividades e utilização dos objetos de aprendizagem, aplicou-se o questionário com os estudantes participantes. Este foi disponibilizado por meio de um formulário online e suas respostas foram registradas de forma individual durante três dias ao fim do experimento.

\section{Resultados e discussões}

Realizado o experimento e coletados os dados, os resultados foram compilados e são sintetizados a seguir.

A partir da primeira parte do questionário, foi possível inferir o perfil dos estudantes e sua relação com a tecnologia. O grupo de participantes desta pesquisa foi composto por 6 mulheres e 4 homens, com idades variando entre 19 e 25 anos ou mais, sendo $70 \%$ com idade entre 19 e 24 anos. O primeiro resultado mostra que todos os estudantes têm smartphone e nove dos dez participantes possuem computador portátil (notebook/laptop, netbook ou ultrabook). Por outro lado, apenas quatro alunos possuem computador de mesa (desktop), dois estudantes possuem tablet, e nenhum participante possui $e$-reader. A Figura 4 apresenta a porcentagem de estudantes que possui cada dispositivo.

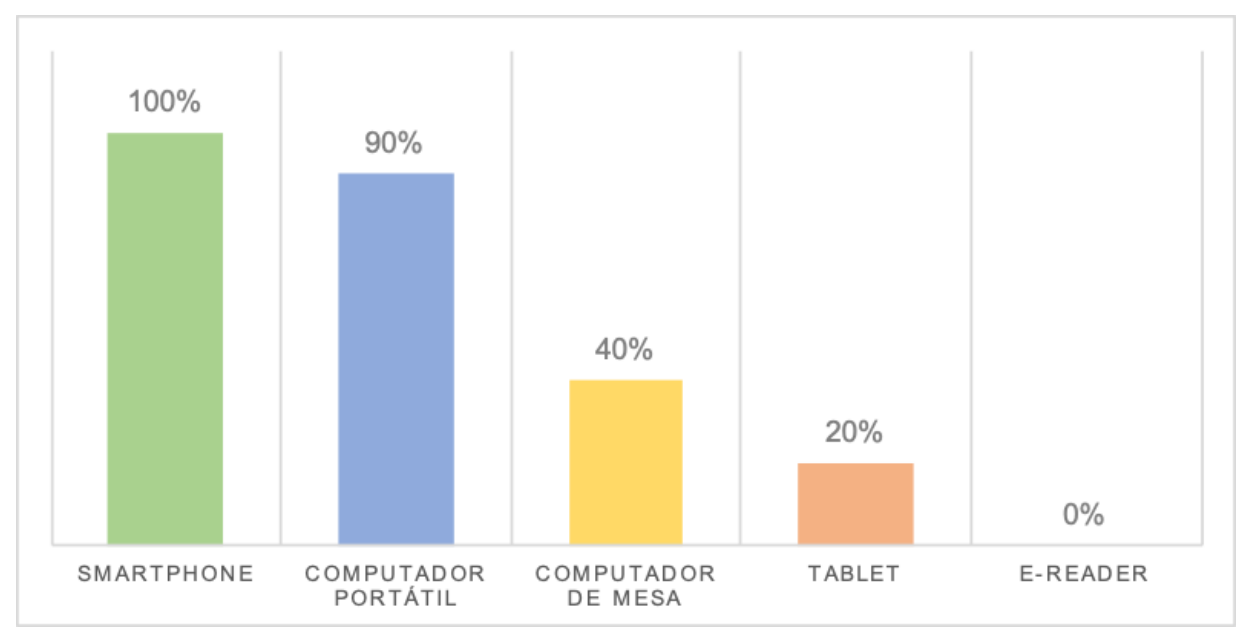

Figura 4: Dispositivos que os estudantes possuem. Fonte: autor com base na pesquisa realizada.

Dos dispositivos que possuem, nove dos dez participantes declararam que o aparato que utilizam com mais frequência é o smartphone, enquanto somente um estudante apontou que utiliza mais seu computador portátil. Além disso, todos os participantes afirmaram utilizar seu 
smartphone para leitura. Nessa perspectiva, 80\% afirmam realizar apenas leituras de textos curtos (notícias, mensagens, etc.) e somente 20\% declararam também utilizar seu smartphone para ler textos longos, como artigos e livros.

Adentrando à segunda parte da pesquisa, cujos dados trazem informações a respeito do uso de smartphone no contexto universitário, todos os participantes afirmaram que levam seu smartphone para a universidade e utilizam-no enquanto estão na instituição. Dentre as atividades realizadas com o dispositivo fora da sala de aula, todos os estudantes apontam que o usam para se comunicar com amigos, colegas, familiares e outras pessoas, além de navegar na internet e nas redes sociais. Já oito dos dez participantes também utilizam o dispositivo móvel para realizar pesquisas na internet, sete para ler textos solicitados pelo professor e seis para tirar fotografias. Apenas quatro estudantes afirmaram usar o smartphone para fazer trabalhos/exercícios de aula, um aluno utiliza como ferramenta de organização (para alarmes, agenda, etc.) e nenhum estudante declarou utilizar o smartphone para jogar jogos enquanto está na universidade.

Todos os estudantes declararam utilizar seus smartphones também durante as aulas. Entretanto, neste contexto, nove afirmam utilizá-lo para realizar pesquisas na internet, oito, para se comunicar com amigos, colegas, familiares e outras pessoas; sete, para ler textos solicitados pelo professor; e seis para fazer trabalhos/exercícios de aula. Por outro lado, em aula, apenas quatro alunos declaram utilizar seus smartphones para navegar na internet e nas redes sociais e somente três para tirar fotografias. Novamente, nenhum aluno declarou utilizar o dispositivo para jogar jogos durante as aulas. A Figura 5 apresenta um comparativo entre as atividades realizadas no smartphone pelos participantes nos contextos dentro e fora da sala de aula, apresentando também um somatório das respostas.

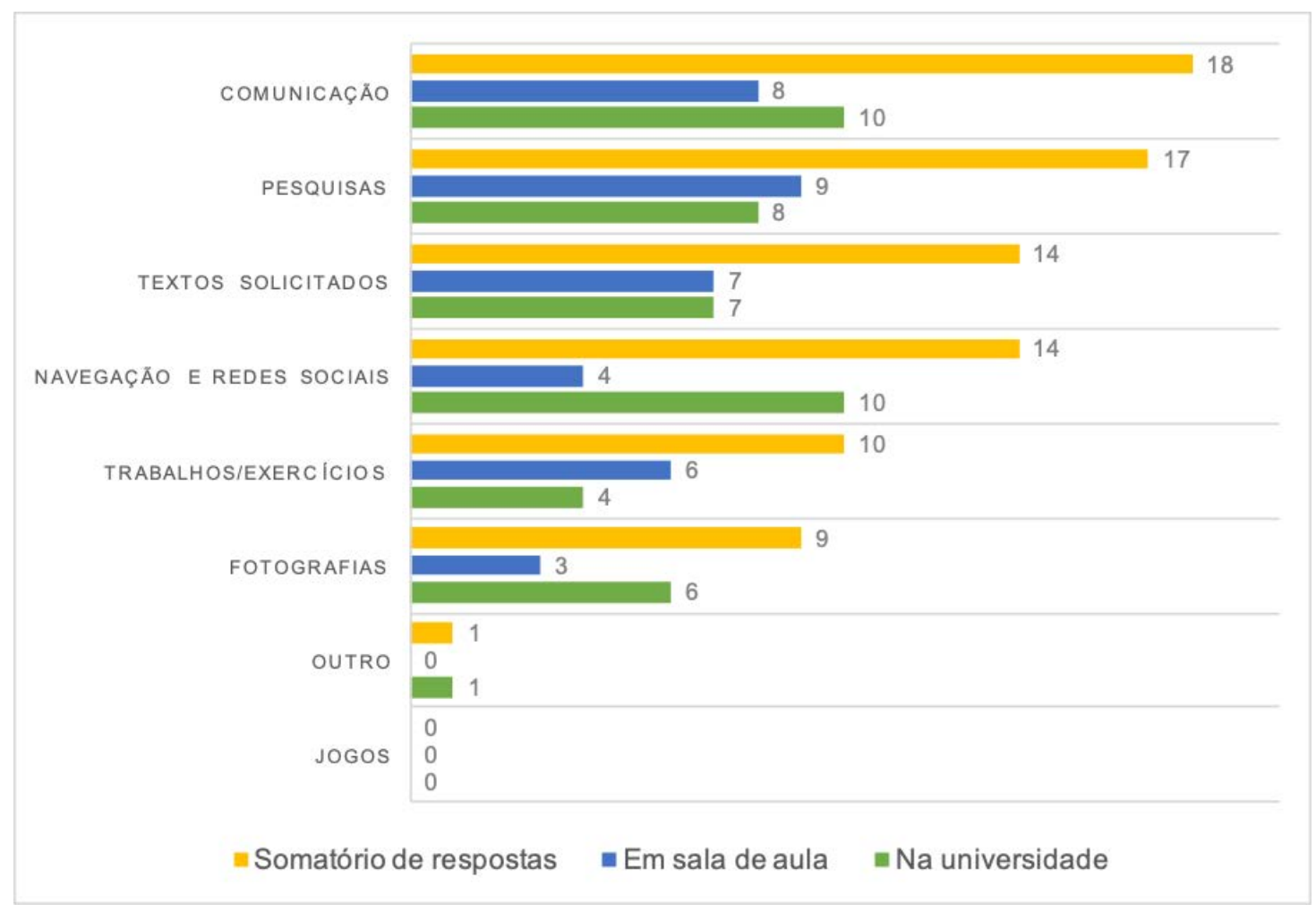

Figura 5: Atividades realizadas no smartphone no contexto universitário. Fonte: autor com base na pesquisa realizada.

Em relação à estratégia de mobile learning proposta, nove dos dez estudantes fizeram uso de ao menos um dos materiais disponibilizados e apenas um aluno declarou não ter usado dispositivos móveis para acessar os conteúdos necessários às atividades. $\mathrm{O}$ estudante que não 
utilizou afirmou que não o fez, porque prefere imprimir o material, de modo a fazer anotações ou ler em um computador em razão do tamanho do texto. De toda forma, ainda que não tenha aderido ao mobile learning, o participante achou relevante/pertinente a disponibilização dos materiais otimizados em função da facilidade de acesso, da mobilidade e da otimização do tempo.

Já dentre os nove estudantes que fizeram uso dos materiais otimizados, seis alunos acessaram todos os objetos, um utilizou somente dois textos e dois fizeram uso de somente um material (Figura 6)

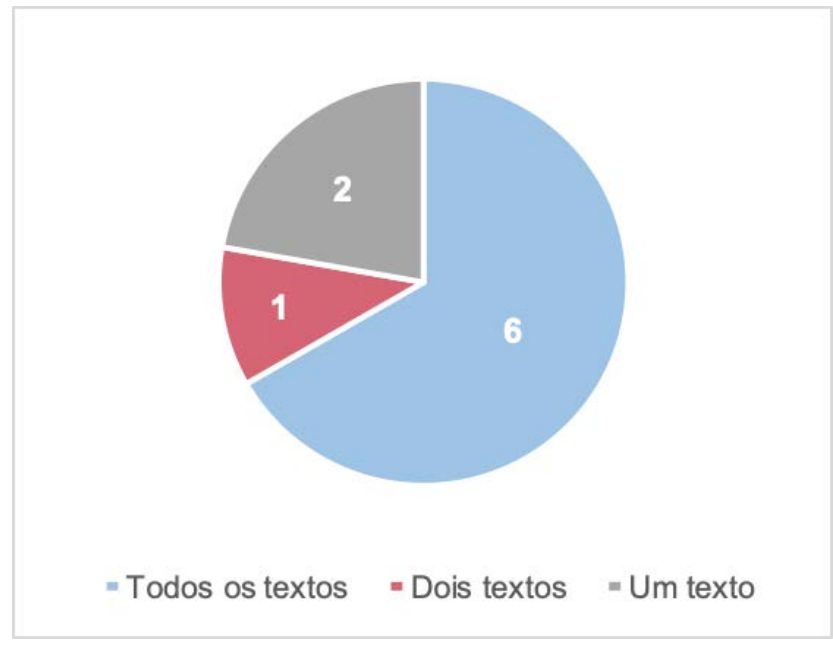

Figura 6: Alunos que acessaram os objetos. Fonte: autor com base na pesquisa realizada.

Ainda, todos que utilizaram os materiais de m-learning o fizeram para leitura com a finalidade de resumo, sete para leitura com objetivo de discussão e seis para estudo de prova (Figura 7)

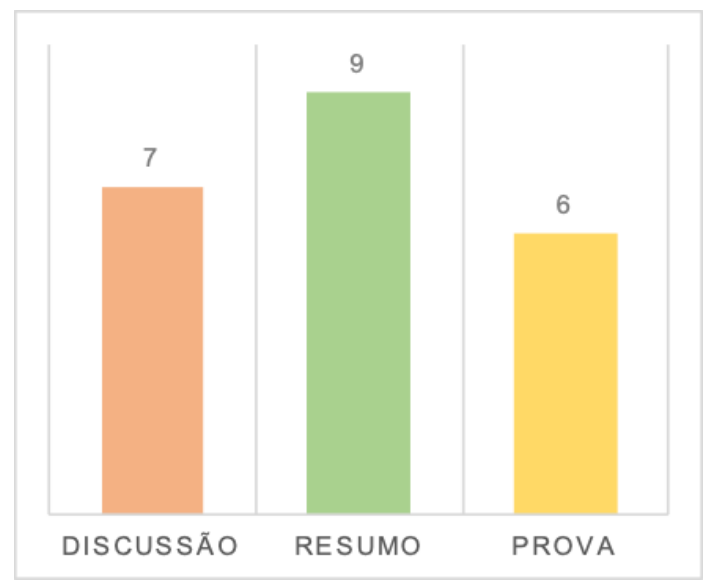

Figura 7: Finalidade dos textos acessados. Fonte: autor com base na pesquisa realizada.

Todos os nove estudantes que utilizaram os materiais otimizados perceberam vantagens no seu uso e acharam sua disponibilização relevante/pertinente, ainda que um participante tenha apontado que smartphones e tablets dispersam a atenção. A mobilidade foi apontada como a principal vantagem no uso dos materiais propostos e também como a principal justificativa para a relevância/pertinência da disponibilização de objetos otimizados para dispositivos móveis, apontada por oito estudantes. A facilidade de acesso foi percebida como uma vantagem por sete estudantes e apontada como uma justificativa para relevância/pertinência por oito. Já a economia financeira foi uma vantagem percebida por oito alunos, pois elimina a necessidade de pagar pela impressão do material, e apontada como motivo para relevância/pertinência por 
seis. A otimização do tempo, por sua vez, foi uma vantagem percebida por seis participantes e indicada como justificativa para a relevância/pertinência por sete. Apenas um estudante percebeu a interação social como uma vantagem no uso dos materiais propostos, mas três indicaram que este é um motivo para a pertinência/relevância do mobile learning. Finalmente, um participante percebeu a leitura em meio eletrônico como vantajosa para a realização de resumos (resposta “outro").

A Figura 8 mostra o comparativo entre as vantagens percebidas e os motivos apontados para a relevância/pertinência da disponibilização do material otimizado, a partir da visão dos nove participantes que fizeram uso dos mesmos.

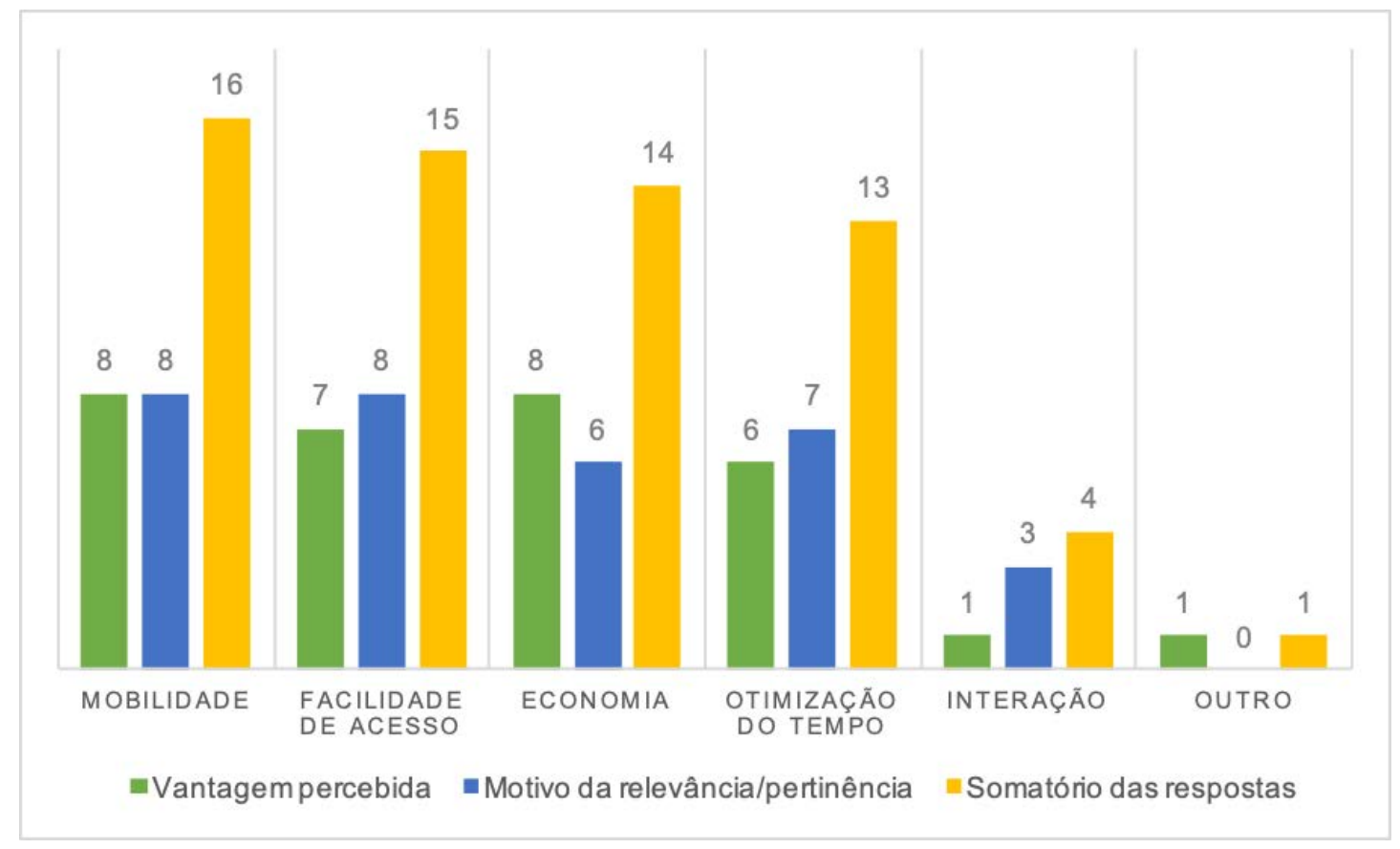

Figura 8: Vantagens percebidas e motivos para relevância/pertinência do mobile learning. Fonte: autor com base na pesquisa realizada.

Como justificativa para a não utilização dos materiais otimizados, dois dos três alunos que não utilizaram ao menos um material apontaram que não gostam de ler no smartphone ou tablet, pois é desconfortável, e que o material era muito extenso para ser lido nestes dispositivos. Ainda, um estudante destacou que preferiu imprimir o texto 03, pois poderia ser relevante para eventuais consultas em sala de aula durante a prova, e outro estudante justificou a não utilização ao afirmar que não fez a atividade correspondente.

Por fim, todos os dez participantes da pesquisa concordam que smartphones e tablets são adequados para pesquisa em sala de aula e contexto universitário como um todo. Além disso, nove alunos afirmam que estes dispositivos também são próprios a leitura de textos, realização de exercícios, bem como para atividades de estudo. Em relação aos comentários adicionais, um aluno destacou o auxílio à comunicação que os smartphones trazem a um agrupamento de pessoas. Finalmente, outro participante alertou que ainda prefere ler textos impressos, mesmo que tenha realizado a leitura de um material otimizado em um dispositivo móvel.

\subsection{Discussões}

Com base nos resultados obtidos nesta pesquisa, foi possível confirmar inicialmente a grande penetração dos smartphones e outros dispositivos móveis, condizendo com as exposições de Saccol et al. (2011), Costa et al. (2015), Becker et al. (2017) e as pesquisas trazidas por Delloite (2018) e Galanek, Gierdowski, e Christopher Brooks (2018). Todos os estudantes participantes 
deste estudo têm o aparelho e 90\% deles possuem computador portátil. É interessante notar, porém, que tablets ainda têm uma participação bastante inferior e e-readers não se fizeram presentes. Isso corresponde à menor popularidade destes dispositivos observada no contexto brasileiro de uma maneira geral.

Além disso, o smartphone é o aparelho utilizado com maior frequência pela maior parte dos participantes, sendo levado e usado também na universidade, dentro e fora da sala de aula. Durante as aulas, os estudantes utilizam-no majoritariamente par realizar pesquisas, comunicarse e ler textos e materiais solicitados pelo professor. Enquanto fora da sala de aula, seus maiores usos são para a navegação, redes sociais e comunicação. A pesquisa e a leitura de textos também aparecem como utilizações frequentes dos universitários quando na instituição. Ressalta-se, porém, que em relação à leitura, o smartphone ainda é utilizado para ler somente textos curtos, como mensagens e notícias, como apontaram $80 \%$ dos participantes.

Percebe-se, portanto, que os estudantes universitários utilizam seu smartphone principalmente como ferramenta de pesquisa e comunicação enquanto estão em sala de aula. Já fora dela, mas ainda dentro da universidade, o dispositivo é utilizado sobretudo para atividades de navegação e redes sociais. De modo geral, a comunicação é destaque no uso do aparelho.

Em relação à estratégia de mobile learning, nove dos dez participantes optaram pelos materiais otimizados. Deste grupo, a maioria usou todos os objetos de aprendizagem disponibilizados, enquanto oito dos nove adeptos utilizaram ao menos dois dos três textos ofertados. Isso mostra a aderência voluntária dos estudantes ao mobile learning, visto que os participantes não tinham ciência do que se tratava a pesquisa durante a realização do experimento.

Quanto à finalidade dos objetos mais acessados, aquele que teve maior uso foi o texto cujo objetivo fora a realização de uma resenha-resumo. Isto pode indicar que ler em dispositivos móveis para esta finalidade pode encontrar maior aceitação dentre os estudantes universitários. No entanto, nota-se que este estudo não permite afirmar tal hipótese.

A mobilidade física, a facilidade de acesso e a otimização do tempo (mobilidade temporal) foram indicadas pelos estudantes tanto como vantagens percebidas quanto como motivos para a relevância/pertinência da utilização do mobile learning. Tal como apontado na literatura por Saccol et al. (2011), estas são potencialidades bastante evidentes da aprendizagem por meio de dispositivos móveis. Destaca-se que outra qualidade trazida por grande parte dos participantes foi a economia financeira, visto que o acesso eletrônico aos conteúdos evita o gasto com impressão e fotocópia de materiais em papel.

Observa-se que a interação, registrada na literatura também como mobilidade sociointeracional (Saccol et al., 2011), apareceu como vantagem do mobile learning na percepção de somente um dos estudantes. Por outro lado, como motivos para pertinência/relevância, três dos dez participantes apontaram este atributo. A baixa percepção talvez tenha se dado em razão de que o objeto desenvolvido, majoritariamente textual, era pouco favorável à interação entre os participantes. Os resultados obtidos, porém, indicam que este potencial de interação simultânea no mobile learning já é conhecido dos estudantes universitários, corroborando com Kukulska-Hulme (2005) no sentido que as possibilidades trazidas pelos dispositivos móveis são as inovações da aprendizagem móvel.

Em relação aos motivos para a não-utilização do mobile learning, esta pesquisa apontou a relação que os indivíduos ainda possuem com os materiais impressos ao se tratar de leitura textual. A realização de anotações e a adequação do corpo de texto para maior conforto de leitura apareceram como necessidades teoricamente não supridas nos dispositivos móveis. Contudo, isso demonstra certa falta de afinidade com a tecnologia vigente por parte dos 
estudantes, visto que determinados formatos de arquivo digital, tal como o formato EPUB utilizado em dois dos três textos disponibilizados - já permitem tais funcionalidades nos dispositivos ou softwares leitores. Além disso, a leitura textual longa em smartphones e tablets, de maneira geral, ainda apresenta resistência por parte de alguns estudantes.

Por fim, destaca-se que a maioria dos estudantes participantes deste estudo concordaram que os dispositivos móveis são adequados para uso no contexto universitário - tal como expuseram Crompton e Traxler (2018) -, especialmente para a realização de pesquisas, mas também para a leitura, realização de exercícios/trabalhos e para o estudo, ainda alguns se mostrem resistentes ao ato de ler por meio de telas eletrônicas.

\section{Conclusões}

Os dispositivos móveis fazem parte do cotidiano da maioria dos indivíduos que vivem na sociedade contemporânea, especialmente os jovens. Por sua vez, inseridos nas universidades, os estudantes da nova geração demandam uma aprendizagem por meio de soluções didáticas que acompanhem seu contexto para além dos limites da sala de aula. Nessa perspectiva, o uso de dispositivos móveis nos processos de ensino e aprendizagem - o mobile learning, ou aprendizagem móvel - se apresenta como uma possibilidade adequada a estes tempos.

De toda forma, na adoção de qualquer estratégia didática, é necessário ao professor uma visão crítica em relação à mesma, de modo a ponderar sua adequação ao contexto em que se inserem os aprendizes, bem como a relevância e a aplicabilidade de tal recurso de ensino e aprendizagem. Assim, o mesmo se aplica ao mobile learning.

Diante disso, este estudo teve por objetivo inferir a percepção estudantil quanto à relevância e aderência do mobile learning no contexto do ensino superior brasileiro. Nessa direção, por meio do experimento realizado, foi possível perceber que o mobile learning se mostrou aderente pelos universitários que participaram da pesquisa, dado o amplo uso dos materiais disponibilizados. Além disso, a aprendizagem móvel foi considerada relevante e pertinente na percepção dos participantes, principalmente em razão das mobilidades física e temporal e da facilidade de acesso, mas também devido a economia financeira que ela permite. É interessante notar que esta última pode estar conectada à conjuntura socioeconômica dos estudantes de instituições públicas de ensino, como no caso deste estudo, cabendo aprofundamentos em pesquisas futuras.

É importante reforçar estas conclusões se dão a partir do universo específico desta pesquisa, considerando suas particularidades, sobretudo o contexto de uma disciplina teórica de um curso de graduação de caráter aplicado inserido em uma instituição pública brasileira. Nesse sentido, os resultados obtidos a partir das realidades dos participantes em outros contextos (como em turmas maiores, cursos de outra natureza, outros tipos de instituições de ensino superior, diferentes níveis de ensino e outros países) podem divergir destes aqui apresentados.

Destaca-se a limitação deste estudo em relação ao objeto de aprendizagem desenvolvido, predominantemente textual, e consequentemente a pouca exploração do potencial do mobile learning. Materiais mais dinâmicos, que façam maior uso das potencialidades do meio digital, aproveitando as possibilidades interativas e multimídia podem estabelecer a aprendizagem móvel de forma mais sedimentada, visto que a leitura textual ainda está muito ligada ao meio impresso. No contexto de pesquisas futuras, pode-se avaliar a experiência do usuário dos estudantes no que diz respeito ao mobile learning para ponderar a adoção de metodologias mais ativas em sala de aula, tais como estratégias de gamificação e a utilização de realidade virtual e/ou aumentada. 
Convém ressaltar que esta pesquisa se desenvolveu a partir de um experimento em uma única disciplina, o que limitou o número e o perfil dos participantes. Isto poderia colaborar para vieses cognitivos e consequentemente a obtenção de dados viciados, inviabilizando conclusões genéricas com base nos resultados. De todo modo, não se buscou com este trabalho inferir considerações universais, mas apontar a percepção dos estudantes em um contexto real e específico para permitir inferências iniciais e possibilitar estudos futuros mais aprofundados e/ou abrangentes, além de conclusões mais categóricas.

Finalmente, esta pesquisa pode contribuir para o debate crítico acerca do tema da aprendizagem móvel, questionando-se o uso que o estudante de fato faz do conteúdo disponibilizado por meio de dispositivos móveis, além de auxiliar os docentes universitários a refletir acerca da relevância da adoção do mobile learning em seus contextos de sala de aula. Para continuidade do estudo, sugere-se a aplicação da pesquisa com amostras maiores e sua ampliação a outros contextos universitários, tal como no ensino à distância ou em instituições de ensino superior privadas.

\section{Referências}

Aarreniemi-Jokipelto, P., \& Goulart, E. (2017, October). Localised mobile learning solutions: Responding to the needs of global education. In Brazilian Symposium on Computers in Education (Simpósio Brasileiro de Informática na Educação-SBIE) (Vol. 28, No. 1, p. 374). doi: $\underline{10.5753 / \text { cbie.sbie.2017.374 [GS Search] }}$

Alexander, B. et al. (2019). EDUCAUSE Horizon Report: 2019 Higher Education Edition. Louisville: EDUCAUSE, 2019. [GS Search]

Alvarez, A. G., Dal Sasso, G. T. M., \& Iyengar, M. S. (2017). Persuasive technology in teaching acute pain assessment in nursing: Results in learning based on pre and post-testing. Nurse Education Today, 50, 109-114. doi: 10.1016/j.nedt.2016.12.019 [GS Search]

Arantes, F., Queiroz, D., da Silva, A., \& Freire, F. (2017, October). Usabilidade de Interfaces Responsivas para m-Learning. In Brazilian Symposium on Computers in Education (Simpósio Brasileiro de Informática na Educação-SBIE) (Vol. 28, No. 1, p. 1733). doi: $\underline{10.5753 / \text { cbie.sbie.2017.1733 [GS Search] }}$

Arantes, H., \& Seabra, R. (2016, November). TME: Aplicativo M-Learning para o Estudo de Conceitos Matemáticos com Ênfase no ENEM. In Brazilian Symposium on Computers in Education (Simpósio Brasileiro de Informática na Educação-SBIE) (Vol. 27, No. 1, p. 1). doi: 10.5753/cbie.sbie.2016.1 [GS Search]

Armstrong, M. (2017). Smartphone Addiction Tightens Its Global Grip. Statista. Disponível em: https://www.statista.com/chart/9539/smartphone-addiction-tightens-its-global-grip Acesso em: 20 mar. 2018.

Barbosa, J., Hahn, R., Rabello, S., Pinto, S. C. C., \& Barbosa, D. N. F. (2007). Computação móvel e ubíqua no contexto de uma graduação de referência. Brazilian Journal of Computers in Education, 15(3). doi: 10.5753/rbie.2007.15.3.\%25p [GS Search]

Bartholo, V. F., Amaral, M. A., \& Cagnin, M. I. (2009). Uma contribuição para a adaptabilidade de Ambientes Virtuais de Aprendizagem para Dispositivos Móveis. Brazilian Journal of Computers in Education, 17(02), 36. doi: 10.5753/rbie.2009.17.02.36 [GS Search]

Batista, S. C. F., Behar, P. A., \& Passerino, L. M. (2011). M-learnMat: Aplicação de um Modelo Pedagógico para Atividades de M-learning em Matemática. In Brazilian 
Symposium on Computers in Education (Simpósio Brasileiro de Informática na EducaçãoSBIE) (Vol. 1, No. 1). doi: 10.5753/cbie.sbie.2011.\%25p [GS Search]

Batista, S. C. F., Behar, P. A., \& Passerino, L. M. (2012). M-learnMat: Modelo Pedagógico para Atividades de M-learning em Matemática. In Brazilian Symposium on Computers in Education (Simpósio Brasileiro de Informática na Educação-SBIE) (Vol. 23, No. 1). Acesso em: 21 maio 2019. doi: 10.5753/cbie.sbie.2012.\%25p [GS Search]

Becker, S. A. et al. (2017). NMC Horizon Report: 2017 Higher Education Edition. Austin, Texas: The New Media Consortium. [GS Search]

Corrêa, A. G. D., de Oliveira, P. A., Costa, L., Damon, D. L., \& de Deus Lopes, R. (2015, October). Sistema de Avaliação Didática Acessível Portátil para Pessoas com Deficiência Visual: estudo de caso com a plataforma Android. In Brazilian Symposium on Computers in Education (Simpósio Brasileiro de Informática na Educação-SBIE) (Vol. 26, No. 1, p. 782). doi: $10.5753 /$ cbie.sbie.2015.782 [GS Search]

Costa, S. R. S., Duqueviz, B. C., \& Pedroza, R. L. S. (2015). Tecnologias Digitais como instrumentos mediadores da aprendizagem dos nativos digitais. Revista Quadrimestral da Associação Brasileira de Psicologia Escolar e Educacional, SP, 19, 3, 603-610. doi: $\underline{10.1590 / 2175-3539 / 2015 / 0193912}$ [GS Search]

Crompton, H., \& Burke, D. (2018). The use of mobile learning in higher education: A systematic review. Computers \& Education, 123, 53-64. doi: 10.1016/j.compedu.2018.04.007 [GS Search]

Crompton, H., \& Traxler, J. (2018). Mobile learning and higher education: Challenges in context. Nova York: Routledge. [GS Search]

Cruz, J., \& Rodrigues, W. (2016, November). Objetos de Aprendizagem Moveis Uma análise de requisitos funcionais para auxiliar os desenvolvedores. In Brazilian Symposium on Computers in Education (Simpósio Brasileiro de Informática na Educação-SBIE) (Vol. 27, No. 1, p. 150). doi: 10.5753/cbie.sbie.2016.150 [GS Search]

Da Silva, J. B., Rochadel, W., Simão, J. P. S., \& Vaz Da Silva Fidalgo, A. (2014). Adaptation model of mobile remote experimentation for elementary schools. Revista Iberoamericana de Tecnologias Del Aprendizaje, 9(1), 28-32. doi: 10.1109/RITA.2014.2302053 [GS Search]

De Lima Ferreira, A. P., Diniz, J. R. B., \& Franca, S. V. A. (2016). M-learning supporting a culture of sustainable water consumption. In 2016 8th Euro American Conference on Telematics and Information Systems, EATIS 2016. doi: 10.1109/EATIS.2016.7520149 [GS Search]

De Moura, V. A. B., \& Peres, L. M. (2017). Evaluation of the impact of retroaction in learning supported by an educational tool. Brazilian Journal of Computers in Education, 25(01), 60. doi: $\underline{10.5753 / \text { rbie.2017.25.01.60 [GS Search] }}$

Delloite. (2018). Global Mobile Consumer Survey 2018: A mobilidade no dia a dia do brasileiro. São Paulo. Disponível em: https://www2.deloitte.com/br/pt/pages/technologymedia-and-telecommunications/articles/mobile-survey.html. Acesso em: 21 maio 2019.

Dias, R. A. (2014). Tecnologias Móveis. Disponível em: http://artigos.netsaber.com.br/resumo_artigo_17302/artigo_sobre_tecnologias_moveis. Acesso em: 23 jun. 2017.

Elsevier. (2019). What is Scopus about? - Scopus: Access and use Support Center. Disponível em: https://service.elsevier.com/app/answers/detail/a_id/15100/. Acesso em 28 jun. 2019. 
Freire, P. S. (2013). Aumente a qualidade e a quantidade de suas publicações científicas. Manual para elaboração de projetos e artigos científicos. (1a ed). Curitiba: CRV. [GS Search]

Galanek, J., Gierdowski, D., \& Christopher Brooks, D. (2018). ECAR Study of Undergraduate Students and Information Technology, 2018. Research report. Louisville: ECAR. Disponível em: https://www.educause.edu/ecar/research-publications/ecar-study-ofundergraduate-students-and-information-technology/2018/introduction-and-key-findings. Acesso em: 21 maio 2019.

Garcia, M. F., Rabelo, D. F., Silva, D. da., \& Amaral, S. F. do. (2011). Novas competências docentes frente às tecnologias digitais interativas. Teoria e Prática da Educação, Campinas, 14, 1, 79-87. [GS Search]

Gaspar, W., Oliveira, E., \& Oliveira, K. (2015, October). Aprendizagem da Língua Portuguesa com Dispositivos Móveis: Um Mapeamento Sistemático da Literatura. In Brazilian Symposium on Computers in Education (Simpósio Brasileiro de Informática na EducaçãoSBIE) (Vol. 26, No. 1, p. 140). doi: 10.5753/cbie.sbie.2015.140 [GS Search]

Gil, A. C. (2008). Métodos e técnicas de pesquisa social. (6a ed). São Paulo: Atlas. [GS Search]

International Digital Publishing Forum. (2017). EPUB. Disponível em: http://idpf.org/epub Acesso em: 25 jan. 2018.

Junior, J. B., Coutinho, C., \& Alexandre, D. (2006). M-learning e webquests. As novas tecnologias como recurso pedagógico. In Brazilian Symposium on Computers in Education (Simpósio Brasileiro de Informática na Educação-SBIE) (Vol. 1, No. 1, pp. 70-72). doi: 10.5753/cbie.sbie.2006.70-72 [GS Search] Acesso em: 21 maio 2019.

Kukulska-Hulme, A. (2005). Introduction. In: Kukulska-Hulme, A.; Traxler, J. Mobile learning: A handbook for educators and trainers. Londres: Routledge. [GS Search]

Leite, B. S. (2014). M-Learning: the use of mobile devices as a didactic tool in the teaching of chemistry. Brazilian Journal of Computers in Education, 22(03), 55. doi: 10.5753/rbie.2014.22.03.55 [GS Search]

Machado, L. R., da Silva Mendes, J. S., Sampaio, D. C. F., Grande, T. P. F., \& Behar, P. A. (2017). M-learning and the elderly: Construction of inclusive pedagogies. Smart Innovation, Systems and Technologies, 75, 391-399. doi: 10.1007/978-3-319-59451-4_39 [GS Search]

Magda, A. J., \& Aslanian, C. B. (2018). Online college students 2018: Comprehensive data on demands and preferences. Louisville: The Learning House, Inc. Disponível em: https://www.learninghouse.com/knowledge-center/research-reports/ocs2018/. Acesso em: 21 maio 2019.

Marçal, E., de Lima, L., Júnior, M., Viana, W., Andrade, R., \& Ribeiro, J. W. (2009, November). A Utilização de Dispositivos Móveis com Ambientes Tridimensionais como Ferramenta para Favorecer o Ensino de Hardware. In Brazilian Symposium on Computers in Education (Simpósio Brasileiro de Informática na Educação-SBIE) (Vol. 1, No. 1). doi: 10.5753/cbie.sbie.2009.\%25p [GS Search]

Mcgraw-Hill Education. (2016). McGraw-Hill Education 2016 Digital Study Trends Survey: Prepared by Hanover Research. Disponível em: https://s3.amazonaws.com/ecommerceprod.mheducation.com/unitas/highered/explore/sites/study-trends/2016-digital-trendssurvey-results.pdf Acesso em: 17 jul. 2017. 
Mülbert, Ana Luisa, \& Pereira, Alice T. C. (2011). Um panorama da pesquisa sobre aprendizagem móvel (m-learning). In: Associação Brasileira de Pesquisadores em Cibercultura, 2011, Florianópolis. Anais do V Simpósio Nacional da ABCiber. [GS Search] Acesso em: 23 jun. 2017.

Nicolete, P., Tarouco, L. M. R., \& dos Santos, A. C. (2018, October). Mobile Learning: Explorando as possibilidades do App Inventor para a criação de objeto educacional móvel. In Brazilian Symposium on Computers in Education (Simpósio Brasileiro de Informática na Educação-SBIE) (Vol. 29, No. 1, p. 1801). doi: 10.5753/cbie.sbie.2018.1801 [GS Search]

Oliveira, E., Diniz, J., \& Falcão, T. (2016). Teaching and learning through mobile devices in the field of law: A systematic literature review [Ensino e aprendizagem através de dispositivos móveis no ramo do direito: Uma revisão sistemática da literatura]. In CEUR Workshop Proceedings (Vol. 1667, pp. 244-256). [GS Search] Acesso em: 21 maio 2019.

Prensky, M. (2001). Digital natives, digital immigrants. On the Horizon, 9, 5, 1-6. doi: $\underline{10.1108 / 10748120110424816 \text { [GS Search] }}$

Rachid, C. L., \& Ishitani, L. (2012). m-tutorial: An Authoring Tool for m-learning Tutorial Development. Brazilian Journal of Computers in Education, 20(1), 17. doi: $\underline{\text { 10.5753/rbie.2012.20.1.17 [GS Search] }}$

Ribeiro, A. C. R., Sonego, A. H. S., Machado, L. R., \& Behar, P. A. (2018). Pedagogical strategies for M-learning: A learning object aimed at teachers' training [Estratégias pedagógicas para a M-learning: Um objeto de aprendizagem voltado para a formação de professores]. In CICIC 2018 - Octava Conferencia Iberoamericana de Complejidad, Informatica y Cibernetica, Memorias (Vol. 2, pp. 166-171). [GS Search] Acesso em: 21 maio 2019.

Ribeiro, P. D. S., Franciscato, F. T., Mozzaquatro, P. M., \& Medina, R. D. (2009, November). Validação de um ambiente de Aprendizagem Móvel em Curso a Distância. In Brazilian Symposium on Computers in Education (Simpósio Brasileiro de Informática na EducaçãoSBIE) (Vol. 1, No. 1). doi: $\underline{0.5753 / \text { cbie.sbie.2009.\%25p [GS Search] }}$

Saccol, A. Z, Schlemmer, E, \& Barbosa, J. (2011). M-Learning e U-Learning: Novas Perspectivas da Aprendizagem Móvel e Ubíqua. São Paulo: Pearson Prentice Hall. [GS Search]

Santaella, L. (2011). Entrevista concedida à Revista IHU online. Revista Digital de Tecnologias Cognitivas, 5, 125-129. Disponível em: http://www4.pucsp.br/pos/tidd/teccogs/entrevistas/2011/edicao_5/lucia_santaella.pdf Acesso em: 15 jun. 2017.

Scopel, M., Kratz, R., \& Pinto, S. C. C. (2006, November). WSMEL: uma arquitetura para integração de serviços educacionais em ambientes de M-Learning. In Brazilian Symposium on Computers in Education (Simpósio Brasileiro de Informática na Educação-SBIE) (Vol. 1, No. 1, pp. 82-84). doi: 10.5753/cbie.sbie.2006.82-84 [GS Search]

Silva, F., da Silva, J. K. M., Lucena, M., \& Gomes, A. (2015, October). Requisitos para Integração entre Ambientes de Aprendizado e m-Learning: uma Revisão Sistemática da Literatura. In Brazilian Symposium on Computers in Education (Simpósio Brasileiro de Informática na Educação-SBIE) (Vol. 26, No. 1, p. 269). doi: 10.5753/cbie.sbie.2015.269 [GS Search] 
Silva, L. C., Neto, F. M. M., \& Júnior, L. J. (2013). MobiLE: a mobile learning multi agent environment based in genetic algorithm to support ubiquitous learning. Brazilian Journal of Computers in Education, 21(01), 62. doi: 10.5753/rbie.2013.21.01.62 [GS Search]

Sousa, Andreia Glória Morais de. (2014) Mobile Learning: Recetividade e Predisposição do Ensino Superior para a sua Utilização. 2014. 114 f. Dissertação (Mestrado) - Curso de Mestrado em Gestão e Desenvolvimento de Recursos Humanos, Escola Superior de Estudos Industriais e de Gestão, Instituto Politécnico do Porto, Vila do Conde. [GS Search]

Traxler, J. (2013). Mobile Learning: Shaping the Frontiers of Learning Technologies in Global Context. In: Huang, R., Kinshuk, \& Spector, J.M (Eds.), Reshaping Learning: New Frontiers of Educational Research. Berlin, Heidelberg: Springer. doi: 10.1007/978-3-64232301-0_10 [GS Search]

Veen, W., \& Vrakking, B. (2009). Homo Zappiens: educando na era digital. Trad. de Vinícius Figueira. Porto Alegre: Artmed. [GS Search]

Vieira, D. V. (2017). Learning based on library automation in mobile Devices: The video production by students of Universidade Federal do Cariri Library Science Undergraduate Degree. Transinformacao, 29(3), 353-363. doi: 10.1590/2318-08892017000300012 [GS Search]

Wischenbart, R., Carrenho C., Celaya, J., Kong Y., \& Kovac, M. (2017). Global eBook 2017: A report on Market trends and developments. Viena: Rüdiger Wischebart Content and Consulting. [GS Search]

Zanela Klein, A., Carlos Da Silva Freitas, J., \& Luis Victoria Barbosa, J. (2015). M-learning in practice: Using SMS for teaching and learning in undergraduate courses. IEEE Latin America Transactions, 13(1), 321-329. doi: 10.1109/TLA.2015.7040665 [GS Search] 